\title{
RELAÇÕES DE INTERFERÊNCIA ENTRE PLANTAS DANINHAS E A CULTURA DO GRÃO-DE-BICO
}

\section{INTERFERENCE RELATIONSHIPS BETWEEN CHICK-PEAS CROP AND WEEDS}

\author{
Carita Liberato do AMARAL ${ }^{1}$; Guilherme Bacarim PAVAN²; Marcelo Claro de SOUZA ${ }^{3}$; \\ José Valcir Fidelis MARTINS ${ }^{4}$; Pedro Luis da Costa Aguiar ALVES ${ }^{5}$ \\ 1. Doutoranda, Universidade Estadual Paulista "Júlio de Mesquita Filho" - UNESP, Jaboticabal, SP, Brasil. caritaliberato@gmail.com; \\ 2. Graduação - UNESP, Jaboticabal, SP, Brasil; 3. Doutor, Universidade de São Paulo - USP, Ribeirão Preto, SP, Brasil; 4. Técnico, \\ Departamento de Biologia Aplicada à Agropecuária - UNESP, Jaboticabal, SP, Brasil; 5. Professor, Doutor, UNESP, Jaboticabal, SP, \\ Brasil.
}

RESUMO: O grão-de-bico consumido no Brasil é quase que totalmente importado. Considerando que algumas regiões do Brasil apresentam condições favoráveis ao desenvolvimento e alta produtividade do grão-de-bico, este trabalho teve como objetivo estudar a interferência de seis plantas daninhas (Amaranthus viridis, Bidens pilosa, Raphanus raphanistrum, Cyperus rotundus, Digitaria nuda e Eleusine indica) sobre o desenvolvimento do grão-de-bico. Foram analisados o comprimento da parte aérea, número de folhas, área foliar, teor de clorofila e massa seca das folhas, caule e raíz do grão-de-bico. Observou-se que a convivência com a plantas daninhas afetaram o desenvolvimento da cultura competindo e interferindo no desenvolvimento vegetativo. Dentre as seis espécies estudadas, três (D. nuda, E. indica e A. viridis) mostraram-se mais agressivas evidenciando a necessidade de controle precoce quando no cultivo em áreas com histórico de alta densidade dessas plantas daninhas. Também foi possível verificar que a principal característica afetada pela interferência das plantas daninhas foi a área foliar do grão-de-bico, afetando significativamente o crescimento e desenvolvimento da cultura.

PALAVRAS-CHAVE: Cicer arietinum. Competitividade. Convivência. Manejo cultural.

\section{INTRODUÇÃO}

A produção de grão-de-bico no Brasil é quase que inexistente (FAO, 2014), com apenas alguns relatos verbais de produção familiar na região Sul do país. No entanto, pesquisadores relatam potencialidades de produção comercial em outras regiões brasileiras (CAMPOS; CANÉCHIO FILHO, 1987; MIYASAKA; MASCARENHAS, 1977; NASCIMENTO et al. 1994; VIEIRA et al, 1999).

Para viabilizar uma produção rentável de grão-de-bico no Brasil torna-se necessário não apenas o desenvolvimento de novas cultivares, mas também o estudo do manejo dessas cultivares. Dentre os manejos de uma cultura, a interferência das plantas daninhas é um dos principais problemas enfrentados pela maioria dos sistemas agrícolas (FORMAGIO et al., 2012). Oerke (2005) constatou que, mundialmente, $38 \%$ do potencial produtivo das lavouras seriam perdidos caso não fossem adotadas medidas de gestão das plantas daninhas. As plantas daninhas podem interferir direta e indiretamente sobre as culturas: diretamente - competindo pelos recursos do meio, principalmente água, luz e nutrientes, depreciando a qualidade do produto colhido; indiretamente - atuando como hospedeiras de pragas, moléstias, nematóides e plantas parasitas e também interferindo nas práticas de colheita (ZANATTA et al., 2006).

$\mathrm{Na}$ cultura do grão-de-bico, o controle eficaz das plantas daninhas pode aumentar sua produtividade de 17 a 105\% (ICARDA-FSP, 1986)

Considerando que o melhor entendimento da interferência de plantas daninhas pode auxiliar na seleção de práticas de manejo eficientes na redução de perdas de produção e redução de impactos ambientais (BAUCOM; HOLT, 2009; VIDAL et al., 2004), o presente trabalho teve como objetivo avaliar a interferência de Amaranthus viridis L., Bidens pilosa L., Raphanus raphanistrum L., Cyperus rotundus L., Digitaria nuda Schumach. e Eleusine indica (L.) Gaertn. sobre o desenvolvimento vegetativo do grão-de-bico cultivado no estado de São Paulo, Brasil.

\section{MATERIAL E MÉTODOS}

O experimento foi conduzido sob condição ambientais não controladas. Como unidades experimentais, foram utilizados vasos de 20 litros de capacidade (diâmetro $34 \mathrm{~cm}$ ), preenchidos com uma mistura de solo (Latossolo Vermelho eutroférrico típico) coletado na camada arável $(0$ a $20 \mathrm{~cm}$ de profundidade), textura argilosa e esterco bovino curtido, na proporção de 3:2 (v:v). Após o preenchimento dos vasos, foi coletada uma amostra 
composta do substrato para ser submetida às análises física e química de rotina, sendo que este substrato continha $\mathrm{pH}: 6,5 ; \mathrm{MO}: 26 \mathrm{~g} \mathrm{dm}^{-3} ; \mathrm{P}$ (resina): $51 \mathrm{mg} \mathrm{dm}^{-3} ; \mathrm{K}, \mathrm{Ca}, \mathrm{Mg}, \mathrm{H}+\mathrm{Al}, \mathrm{SB}$ e T: 1,1 ; $163 ; \quad 73 ; 11 ; 237,1 ; 248,1 \quad \operatorname{mmol}_{\mathrm{c}} \mathrm{dm}^{-3}$ respectivamente; $\mathrm{V}(\%)$ : $96 \%$; e teores de argila, silte, areia fina e areia grossa, respectivamente, de 475; 193; 156 e $176 \mathrm{~g} \mathrm{~kg}^{-1}$. De acordo com os resultados das análises químicas do substrato, foi feita a adubação de semeadura, seguindo a recomendação de Van Raij et al. (1997).

Em cada unidade experimental foram distribuídas três sementes de grão-de-bico da cultivar BRS Cícero (CNPH 91-008)). As sementes foram distribuídas em linha, com espaçamento de 7 cm entre as plantas. As sementes de Amaranthus viridis, Bidens pilosa, Raphanus raphanistrum, Digitaria nuda e Eleusine indica e tubérculos Cyperus rotundus foram semeadas/plantados em bandejas de 128 células preenchidas com substrato hortícola (Plantimax HT). Quando as plântulas encontravam-se com aproximadamente $10 \mathrm{~cm}$, coincidindo com o comprimento da parte aérea das plântulas de grão-de-bico, estas foram transplantadas para os vasos, na mesma proporção e pareadas às plântulas de grão-de-bico, porém distanciadas em $10 \mathrm{~cm}$ entre si (Figura 1).

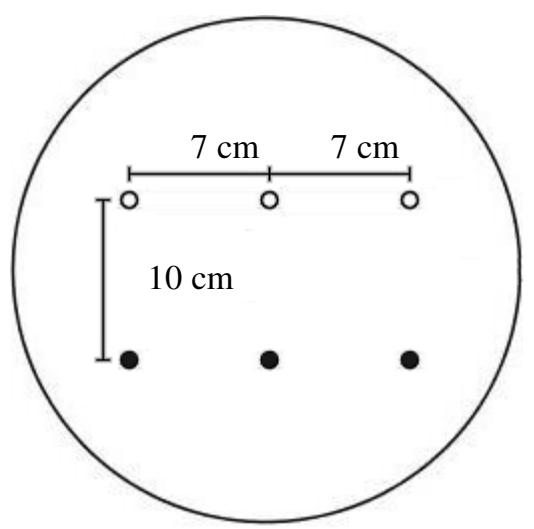

Figura 1. Esquema representando a disposição das plantas nos vasos. $\square$ Grão-de-bico. $\square$ Planta daninha.

Os vasos foram distribuídos em delineamento de blocos casualizados, com seis tratamentos e três repetições. Cada tratamento constituiu na convivência de grão-de-bico com uma das espécies de plantas daninhas, e também foi montado um controle com apenas as plantas de grão-de-bico.

Aos 15, 30, 45, 60, 75 e 90 dias após o plantio (DAP) foram determinados o teor relativo de clorofila total (MINOLTA, SPAD 502) do primeiro folíolo totalmente desenvolvido da terceira folha, o comprimento da parte aérea e o número de folhas das três plantas de grão-de-bico de cada repetição.

Aos 60 e 90 DAP, três plantas de grão-debico de cada tratamento foram retiradas dos vasos, lavadas, separadas em folhas, caules e raízes para avaliação área foliar (Li Cor, LI 3000A) e comprimento radicular. $\mathrm{O}$ material coletado foi seco em estufa de circulação de ar a $70^{\circ} \mathrm{C}$ por $96 \mathrm{~h}$ para a determinação do acúmulo de massa seca das raízes, caule e folhas.

A cada 2 dias os vasos foram irrigados até atingirem a capacidade de campo e aos 30 DAP aplicou-se $50 \mathrm{~g}$ i.a. ha ${ }^{-1}$ de thiamethoxam para o controle de mosca branca. Diariamente, as plantas daninhas que emergiram espontaneamente nas unidades experimentais foram arrancadas manualmente. Aos 30 DAP foi realizada uma adubação de cobertura adicionando-se a cada vaso a quantidade de $5 \mathrm{~g}$ de ureia (VAN RAIJ et al., 1997).

Os dados referentes ao acúmulo de massa seca das raízes, caule e folhas, área foliar e comprimento radicular aos 60 e 90 DAP foram comparados mediante análises de variância e suas médias foram comparadas pelo teste de Tukey a 5\% de probabilidade. Os dados quinzenais referentes às avaliações do teor de clorofila total, número de folhas e comprimento da parte aérea foram submetidos a análises de regressão linear.

Para a verificação dos graus de similaridades entre os tratamentos foram realizadas análises de componentes principais, e análises de agrupamentos hierárquicos,pelo método de ligação média e com base na distância Euclidiana, utilizando o teor de clorofila, comprimento da parte aérea e número de folhas, comprimento das raízes, área foliar, massa seca das folhas, caule e raízes dos tratamentos no grão-de-bico como variáveis (KAISER 1958) 


\section{RESULTADOS E DISCUSSÃO}

Mediante as análises de regressão (Figura 2) observa-se que o teor de clorofila total reduziu ao longo do tempo para todos os tratamentos $(\mathrm{p}<0,05)$ exceto para a testemunha $(p>0,05)$. Considerando as equações, verificou-se que a convivência com todas
AMARAL, C. L. et al.

as plantas daninhas afetaram o teor de clorofila durante o desenvolvimento do grão-de-bico. Os tratamentos com as plantas $D$. nuda e $E$, indica tiveram os valores mais acentuados, sendo que o acréscimo de uma unidade de DAP reduziram 0,44 e 0,47 UR, respectivamente, do teor de clorofila das plantas de grão-de-bico.

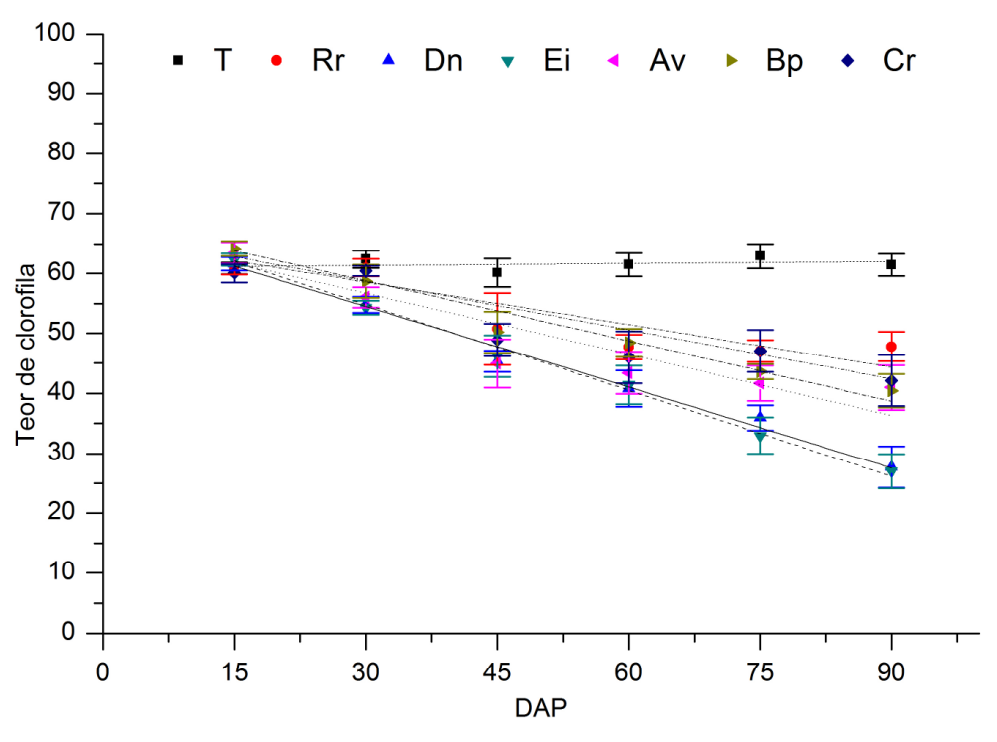

Figura 2. Teor de clorofila (UR) de plantas de grãos-de-bico em função dos períodos de convivência com as plantas daninhas. T: testemunha, $\mathrm{y}=-0,03 \mathrm{x}+61,35, \mathrm{R} 2: 0,11$; Rr: Raphanus raphanistrum, $\mathrm{y}=-$ 0,21x + 63,79, R2: 0,79; Dn: Digitaria nuda, y = - 0,44x + 67,40, R2: 0,98; Ei: Eleusine indica, y = - 0,47x + 68,56, R2: 0,99; Av: Amaranthus viridis, $\mathrm{y}=-0,30 \mathrm{x}+64,11, \mathrm{R} 2:$ 0,79; Bp: Bidens pilosa, $\mathrm{y}=-0,31 \mathrm{x}+67,51, \mathrm{R} 2: 0,96 ;$ Cr: Cyperus rotundus, $\mathrm{y}=-0,25 \mathrm{x}+64,02, \mathrm{R} 2: 0,82$.

A redução dos valores de clorofila das folhas é um indicativo de estresses bióticos ou abióticos que modificam o poder de assimilação de $\mathrm{CO}_{2}$, com alterações fisiológicas na atividade fotossintética (Baker e Rosenqvist, 2004). Quando duas ou mais plantas coexistem em um mesmo ambiente estabelece-se algumas relações estressantes como a competição por recursos essenciais ao desenvolvimento vegetal (ZIMDAHL, 2004). A competição da cultura com as plantas daninhas pelos mesmos recursos, principalmente disponibilidade de nutrientes, pode ter interferido nos valores de teores de clorofila. Tal constatação foi mais evidente a partir da avaliação aos 30 DAP quando se verificou redução do teor de clorofila de todas as plantas que se encontravam em convivência com uma planta daninha, enquanto o valor da testemunha permaneceu constante.
Para as análises de regressão observou-se efeito linear positivo significativo no comprimento da parte aérea (Figura 3 ) de todos os tratamentos e da testemunha $(\mathrm{p}<0,05)$, na qual as plantas que proporcionaram o menor desenvolvimento da parte aérea da cultura foram $A$. viridis, $D$. nuda e $E$. indica, com crescimento de 6,0,6,0 e 5,8 $\mathrm{cm}$ a cada 15 dias, respectivamente, enquanto a testemunha teve o crescimento de $8,8 \mathrm{~cm}$ para o mesmo período.

A convivência com as plantas daninhas afetou o comprimento da parte aérea do grão-debico a partir dos 60 DAP, o que pode significar que até este momento não há efeito de uma espécie sobre a outra, ou seja, a habilidade das espécies em interferir uma sobre a outra é equivalente ou semelhante (AGOSTINETTO et al., 2008; FLECK et al., 2008). 


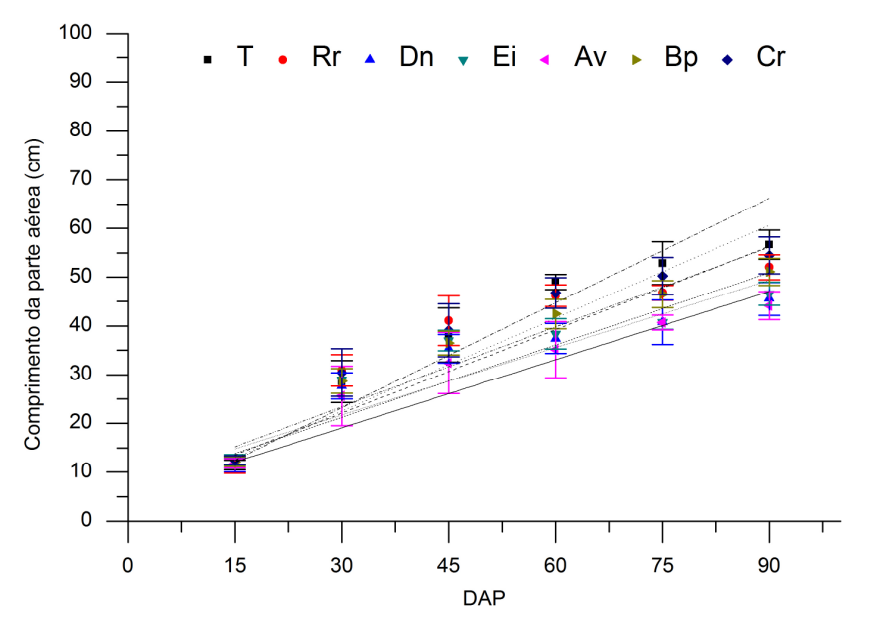

Figura 3. Comprimento da parte aérea $(\mathrm{cm})$ de plantas de grãos-de-bico em função dos períodos de convivência com as plantas daninhas. T: testemunha, $\mathrm{y}=0,59 \mathrm{x}+8,52, \mathrm{R}^{2}: 0,91$; Rr: Raphanus raphanistrum, $\mathrm{y}=0,49 \mathrm{x}+12,57, \mathrm{R}^{2}: 0,81$; Dn: Digitaria nuda, $\mathrm{y}=0,40 \mathrm{x}+11,85, \mathrm{R}^{2}: 0,84$; Ei: Eleusine indica, $\mathrm{y}=0,39 \mathrm{x}+13,43, \mathrm{R}^{2}: 0,81 ;$ Av: Amaranthus viridis, $\mathrm{y}=0,40 \mathrm{x}+10,66, \mathrm{R}^{2}: 0,90$; Bp: Bidens pilosa, $\mathrm{y}=0,48 \mathrm{x}+10,81, \mathrm{R}^{2}: 0,90 ;$ Cr: Cyperus rotundus, $\mathrm{y}=0,53 \mathrm{x}+11,19, \mathrm{R}^{2}: 0,89$.

Mediante as análises de regressão observase que o número de folhas (Figura 4) aumentou linearmente em todos os tratamentos, incluindo a testemunha $(\mathrm{p}<0,05)$. A convivência com as plantas daninhas prejudicou a emissão de folhas, sendo que os tratamentos com $D$. nuda e E. indica foram os mais afetados, com acréscimo de 10 folhas a cada 15 dias, enquanto para as plantas sem convivência com plantas daninhas o aumento foi de 62 folhas a cada 15 dias.
O grão-de-bico apresenta lenta taxa de crescimento e limitado desenvolvimento da área foliar nos estádios iniciais de crescimento $\mathrm{e}$ estabelecimento da cultura (SOLH; PALA, 1990), o que pode proporcionar uma vantagem competitiva as plantas daninhas. Segundo Saxena et al. (1976), o período compreendido entre 30 e 60 dias após a emergência do grão-de-bico é o mais crítico para o controle de plantas daninhas, comprometendo o desenvolvimento da cultura.

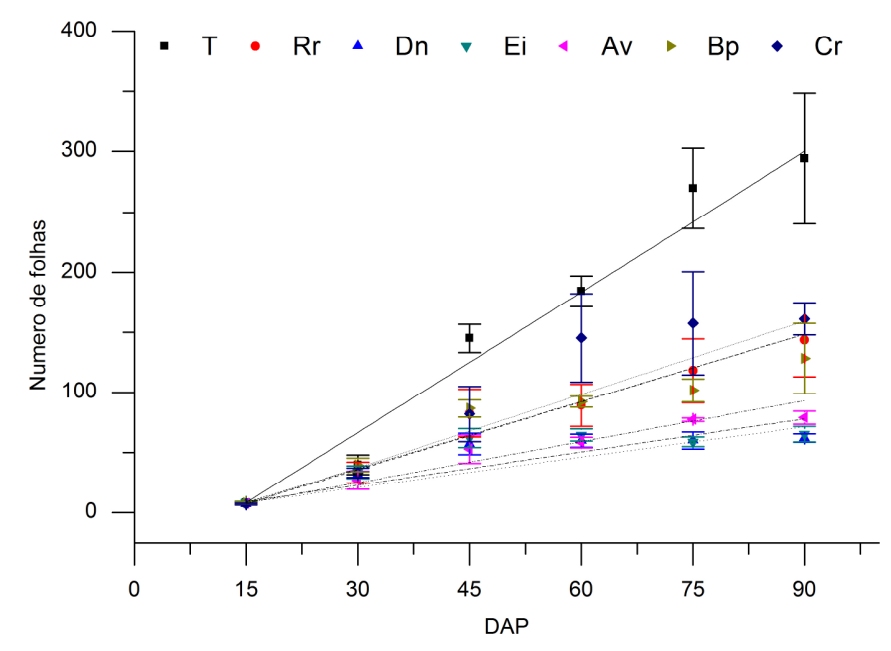

Figura 4. Número de folhas de plantas de grãos-de-bico em função dos períodos de convivência com as plantas daninhas. T: testemunha, $\mathrm{y}=4,11 \mathrm{x}-58,99, \mathrm{R}^{2}: 0,97 ; \mathrm{Rr}$ : Raphanus raphanistrum, $\mathrm{y}=1,79 \mathrm{x}-15,12$, $\mathrm{R}^{2}$ : 0,97; Dn: Digitaria nuda, $\mathrm{y}=0,69 \mathrm{x}+10,10, \mathrm{R}^{2}: 0,69$; Ei: Eleusine indica, $\mathrm{y}=0,69 \mathrm{x}+12,69$, $\mathrm{R}^{2}$ : 0,64; Av: Amaranthus viridis, $\mathrm{y}=0,98 \mathrm{x}-1,13, \mathrm{R}^{2}$ : 0,93; $\mathrm{Bp}$ : Bidens pilosa, $\mathrm{y}=1,51 \mathrm{x}-3,17, \mathrm{R}^{2}$ : 0,91; Cr: Cyperus rotundus, $\mathrm{y}=2,10 \mathrm{x}-23,19, \mathrm{R}^{2}: 0,91$. 
Em relação ao comprimento das raízes das plantas de grão-de-bico (Tabela 4), verificou-se redução quando em convivência com a $C$. rotundus e o D. nuda nas avaliações realizadas aos 60 DAP. A agressividade de $C$. rotundus é tamanha que, em condições edafoclimáticas favoráveis, pode produzir até 3.000 tubérculos $\mathrm{m}^{-2}$ com mais de 2.000 manifestações epígeas por metro quadrado, as quais, quando capinadas, podem crescer de 1 a $3 \mathrm{~cm}$ por dia; o plantio de um único tubérculo é suficiente para formar outros 10 tubérculos em 60 dias
(LORENZI, 1983). Além da rápida propagação de tubérculos, C. rotundus também exsuda aleloquímicos (MUNIZ et al., 2007) que podem prejudicar do desenvolvimento das plantas cultivadas. Aos 90 DAP, apenas as plantas em convivência com $R$. raphanistrum e $B$. pilosa não apresentaram redução no sistema radicular em relação a testemunha (Tabela 4). Observou-se nas plantas em convivência com a $C$. rotundus a maior redução das raízes $(23,86 \%)$ quando comparadas às plantas de grão-de-bico sem convivência.

Tabela 4. Efeito da convivência com as plantas daninhas sobre o comprimento das raízes $(\mathrm{cm})$ de grão-de-bico avaliado aos 60 e 90 dias após o plantio DAP.

\begin{tabular}{lcc}
\hline \multirow{2}{*}{ Tratamentos } & \multicolumn{2}{c}{ Comprimento das Raízes (cm) } \\
\cline { 2 - 3 } & $60 \mathrm{DAP}$ & $90 \mathrm{DAP}$ \\
\hline Testemunha & $46,67 \mathrm{~A}$ & $49,52 \mathrm{~A}$ \\
R. raphanistrum & $44,33 \mathrm{AB}$ & $47,47 \mathrm{AB}$ \\
D. nuda & $39,67 \mathrm{BC}$ & $41,21 \mathrm{BCD}$ \\
E. indica & $41,44 \mathrm{ABC}$ & $41,93 \mathrm{BCD}$ \\
A. viridis & $41,07 \mathrm{ABC}$ & $40,10 \mathrm{CD}$ \\
B. pilosa & $43,00 \mathrm{AB}$ & $45,39 \mathrm{ABC}$ \\
C. rotundus & $36,70 \mathrm{C}$ & $37,70 \mathrm{D}$ \\
\hline Teste F & $5,91 * *$ & $7,85 * *$ \\
DMS & 6,83 & 7,32 \\
CV $(\%)$ & 5,88 & 6,06 \\
\hline
\end{tabular}

Médias seguidas de mesma letra na coluna não diferem entre si ao nível de $5 \%$ de probabilidade pelo Teste de Tukey. Pelo teste $\mathrm{F}$, ** significativo a $1 \%$ de probabilidade. DMS: diferença mínima significativa; CV (\%): coeficiente de variação.

A área foliar (Tabela 5) apresentou redução significativa pela convivência com todas as plantas daninhas em relação às plantas testemunha nas avaliações realizadas aos 60 e 90 DAP. As plantas convivendo com D. nuda, E. indica e A. viridis apresentaram as menores áreas foliares aos 90 DAP (Tabela 5).

Tabela 5. Efeito da convivência com as plantas daninhas sobre a área foliar $\left(\mathrm{cm}^{2}\right)$ de plantas de grão-de-bico avaliada aos 60 e 90 dias após o plantio (DAP).

\begin{tabular}{lcc}
\hline \multirow{2}{*}{ Tratamentos } & \multicolumn{2}{c}{ Área Foliar $\left(\mathrm{cm}^{2}\right)$} \\
\cline { 2 - 3 } Testemunha & $60 \mathrm{DAP}$ & $90 \mathrm{DAP}$ \\
R. raphanistrum & $538,73 \mathrm{~A}$ & $1249,78 \mathrm{~A}$ \\
D. nuda & $292,91 \mathrm{C}$ & $701,48 \mathrm{BC}$ \\
E. indica & $293,80 \mathrm{C}$ & $282,22 \mathrm{D}$ \\
A. viridis & $443,18 \mathrm{~B}$ & $399,62 \mathrm{D}$ \\
B. pilosa & $445,21 \mathrm{~B}$ & $219,93 \mathrm{D}$ \\
C. rotundus & $451,23 \mathrm{~B}$ & $471,59 \mathrm{CD}$ \\
Teste F & $54,51^{* *}$ & $784,50 \mathrm{~B}$ \\
DMS & 114,42 & $42,10^{* *}$ \\
CV $(\%)$ & 8,77 & 266,23 \\
\hline
\end{tabular}

Médias seguidas de mesma letra na coluna não diferem entre si ao nível de 5\% de probabilidade pelo Teste de Tukey. Pelo teste $\mathrm{F}$, ** significativo a $1 \%$ de probabilidade. DMS: diferença mínima significativa; CV (\%): coeficiente de variação.

Aos 60 DAP, foi observado significativa redução no acúmulo de massa seca nas plantas de grão-de-bico em convivência com $A$. viridis e $D$. nuda em relação à testemunha. Ainda aos $60 \mathrm{DAP}$, verificou-se nas análises realizadas diferença significativa na massa seca das raízes (Tabela 6), sendo que as plantas em convivência com o $B$. pilosa apresentaram maior massa seca do que as 
plantas da testemunha, enquanto nas plantas convivendo com D. nuda, E. indica e A. viridis verificou-se redução em relação a testemunha. Isso pode ter ocorrido devido ao fato de que, segundo Teixeira et al. (2009), cada espécie de uma comunidade infestante proporciona uma resposta diferente às variações climáticas e edáficas das diferentes regiões, o que pode influenciar no potencial competitivo de cada espécie.
Aos 90 DAP, as plantas que estavam convivendo com plantas daninhas apresentaram redução massa seca das folhas, caules e raízes que as plantas da testemunha, independentemente da espécie da planta daninha (Tabela 6). Bhan e Kukula (1987) observaram interferência de plantas daninhas reduzindo o acúmulo de massa seca de grão-de-bico.

Tabela 6. Efeito da convivência com as plantas daninhas sobre a massa seca (MS) das folhas, caules e raízes (g) do grão-de-bico avaliada aos 60 e 90 dias após o plantio (DAP).

\begin{tabular}{lcccccc}
\hline \multirow{2}{*}{ Tratamentos } & \multicolumn{2}{c}{ MS das Folhas (g) } & \multicolumn{2}{c}{ MS Caules (g) } & \multicolumn{2}{c}{ MS das Raízes (g) } \\
& $60 \mathrm{DAP}$ & $90 \mathrm{DAP}$ & $60 \mathrm{DAP}$ & $90 \mathrm{DAP}$ & $60 \mathrm{DAP}$ & $90 \mathrm{DAP}$ \\
\hline Testemunha & $3,54 \mathrm{~A}$ & $6,97 \mathrm{~A}$ & $2,71 \mathrm{AB}$ & $8,84 \mathrm{~A}$ & $2,18 \mathrm{BC}$ & $4,95 \mathrm{~A}$ \\
R. raphanistrum & $3,39 \mathrm{~A}$ & $2,99 \mathrm{CD}$ & $3,30 \mathrm{~A}$ & $4,02 \mathrm{C}$ & $3,05 \mathrm{AB}$ & $2,09 \mathrm{BC}$ \\
D. nuda & $1,56 \mathrm{~B}$ & $2,09 \mathrm{CD}$ & $1,31 \mathrm{~B}$ & $2,56 \mathrm{CD}$ & $0,90 \mathrm{D}$ & $1,33 \mathrm{C}$ \\
E. indica & $2,27 \mathrm{AB}$ & $1,95 \mathrm{D}$ & $1,85 \mathrm{AB}$ & $2,54 \mathrm{D}$ & $1,07 \mathrm{D}$ & $0,90 \mathrm{C}$ \\
A. viridis & $1,37 \mathrm{~B}$ & $2,70 \mathrm{CD}$ & $1,06 \mathrm{~B}$ & $2,46 \mathrm{D}$ & $0,74 \mathrm{D}$ & $1,52 \mathrm{C}$ \\
B. pilosa & $2,24 \mathrm{AB}$ & $3,25 \mathrm{C}$ & $2,03 \mathrm{AB}$ & $3,64 \mathrm{CD}$ & $3,30 \mathrm{~A}$ & $2,05 \mathrm{BC}$ \\
C. rotundus & $2,48 \mathrm{AB}$ & $5,04 \mathrm{~B}$ & $2,06 \mathrm{AB}$ & $6,42 \mathrm{~B}$ & $1,20 \mathrm{CD}$ & $3,22 \mathrm{~B}$ \\
\hline Teste F & $6,21 * *$ & $47,68 * *$ & $3,69 *$ & $62,92 * *$ & $25,40 * *$ & $28,90 * *$ \\
DMS & 1,60 & 1,27 & 1,94 & 1,47 & 1,02 & 1,26 \\
CV $(\%)$ & 23,81 & 12,75 & 34,06 & 12,14 & 20,54 & 19,99
\end{tabular}

Médias seguidas de mesma letra na coluna não diferem entre si ao nível de 5\% de probabilidade pelo Teste de Tukey. Pelo teste $\mathrm{F}$, ** significativo a $1 \%$ de probabilidade. DMS: diferença mínima significativa; CV (\%): coeficiente de variação.

A correlação entre a massa seca das plantas daninhas e a massa seca de grão-de-bico, aos 60 DAP (Figura 2 A), foi linear decrescente, ou seja, para massa seca máxima estimada de $6,29 \mathrm{~g}$ para o grão-de-bico, cada grama de massa seca de planta daninha a reduziu em $0,14 \mathrm{~g}$. Para os 90 DAP (Figura 2 B), o efeito foi exponencial decrescente, ou seja, para uma massa seca estimada de 9,28 g,

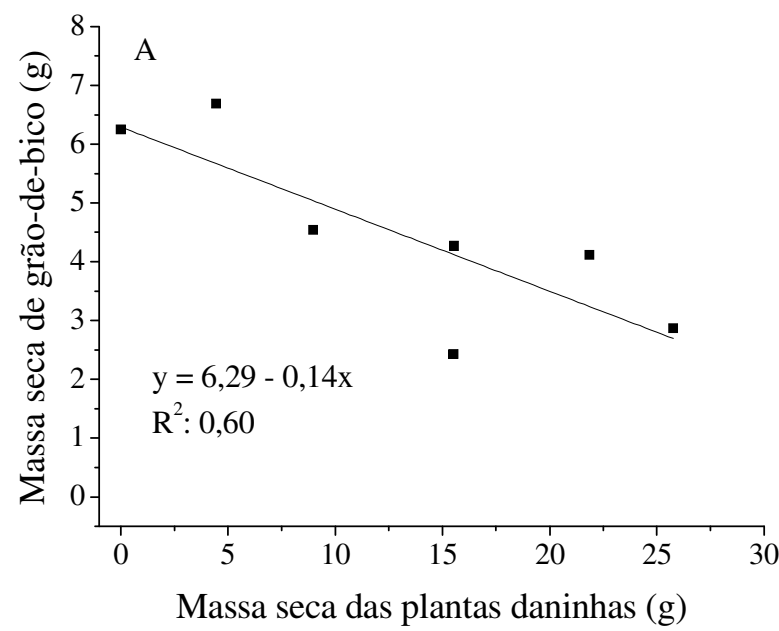

cada g de massa seca de planta daninha a reduziu em 1,61 g até estabilizar em 6,53 g. Meschede et al. (2004) verificaram que o comprimento da parte aérea, número de hastes por planta, estande final e produtividade da soja possui correlação significativa e inversamente proporcional à massa seca das plantas daninhas presentes na área.

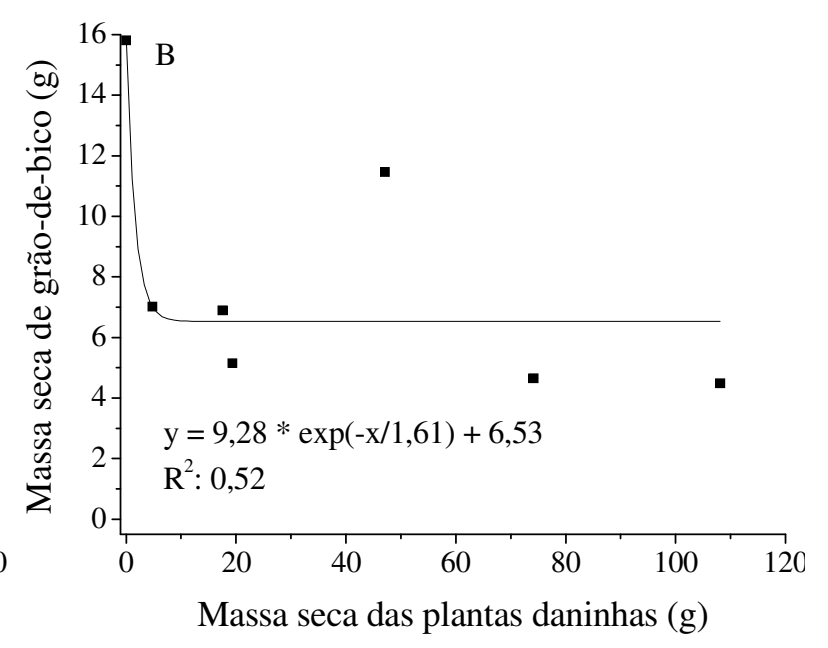

Figura 2. Correlação entre massa seca acumulada pelas plantas de grão-de-bico e massa seca das plantas daninhas, independentemente da espécie, aos 60 (A) e 90 (B) dias após o plantio (DAP). 
Os resultados obtidos pelas análises de agrupamento mostram que, para a avaliação realizada aos 60 DAP (Figura 3 A), é possível observar a separação de dois grupos de tratamentos com comportamentos distintos com relação à interferência das plantas daninhas na cultura (nível 4 na distância Euclidiana). Verificou-se também que a planta de grão-de-bico que encontrava-se sem convivência apresentou maior similaridades com as plantas que estavam em convivência com $R$. raphanistrum e B. pilosa. Ao passo que, aos 90 DAP (Figura 3 B), observa-se a formação de dois grupos principais (nível 4 na distância Euclidiana) além de dois grupos monoespecífico (nível 3 na distância Euclidiana), indicando que estes grupos possuem alto grau de dissimilaridade em relação às outras espécies.

Constatou-se que, o maior índice de similaridade ocorreu entre os tratamentos que formaram os sub-grupos de grão-de-bico em convivência com A. viridis e com $D$. nuda aos 60 DAP (Figura 3 A) e, grão-de-bico em convivência com E. indica e com D. nuda aos 90 DAP (Figura 3 B). A análise de agrupamentos representada na forma de dendograma (Figuras 3) também mostrou que os grupos formados com maior similaridade entre os tratamentos apresentam maior interferência na cultura, causando as maiores reduções na massa seca (Tabela 6).
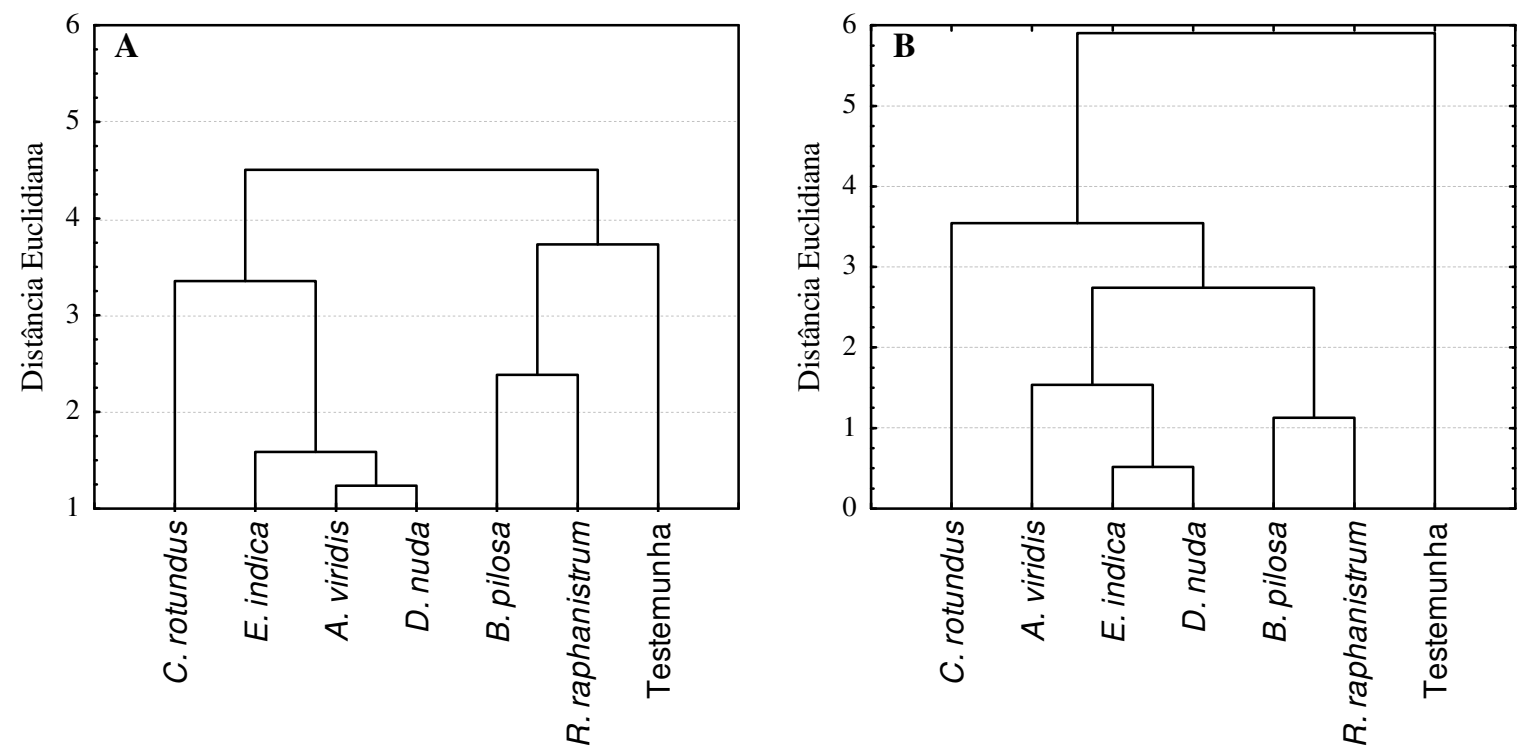

Figura 3. Dendograma resultante da análise de agrupamentos da média das análises de teor de clorofila, comprimento da parte aérea, número de folhas, comprimento das raízes, área foliar, massa seca das folhas, caule e raízes dos tratamentos de grão-de-bico, cultivados em vasos, aos 60 (A) e 90 (B) dias após o plantio (DAP).

A análise de componentes principais das características quantitativas (Figura 4) revelou a formação de grupos semelhante daquele mostrado pelo dendograma (Figura 3) resultante da análise de agrupamento. A análise de componentes principais foi realizada para discriminar os tratamentos que caracterizaram os diferentes grupos demonstrados pela análise de agrupamento.

Aos 60 DAP (Figura 4 A), foi possível discriminar quatro grupos com características diferentes, sendo que os dois primeiros componentes principais apresentou uma variância total de $86 \%$. No primeiro grupo, localizado à esquerda do primeiro componente principal, encontra-se o tratamento testemunha (grão-de-bico sem convivência) isolado e abaixo os tratamentos de convivência com $R$. raphanistrum e com o B. pilosa e, no terceiro, localizado no centro e isolado está o tratamento de convivência com $C$. rotundus, à direita do primeiro componente principal, estão os tratamentos de grão-de-bico convivendo com $D$. nuda, E. indica e A. viridis.

$\mathrm{Na}$ análise de componentes principais aos 90 dias DAP (Figura 4 B), com 94,63\% da variância total retida nos dois primeiros componentes principais, os tratamentos de grão-debico com convivência com $B$. pilosa e $R$. raphanistrum apresentam características intermediárias entre esses dois grupos ou mesmo características de transição, o que não permitiu 
discriminá-los. A avaliação aos 90 DAP apresentou comportamento semelhante dos tratamentos aos 60
DAP (Figura 4 A).
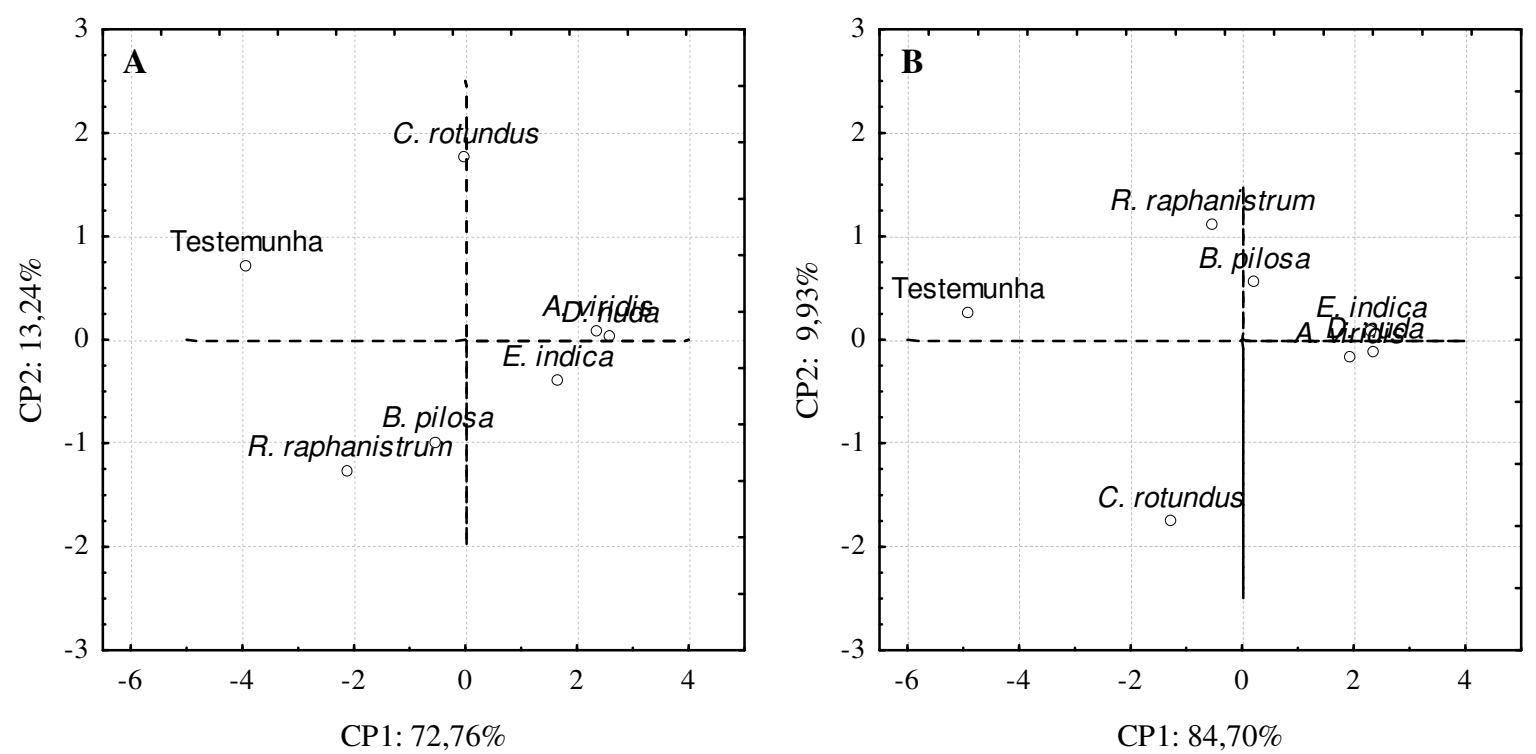

Figura 4. Representação gráfica da dispersão dos tratamentos utilizando-se os dois primeiros componentes principais (CP1 e CP2) para a avaliação aos 60 (A) e 90 (B) dias após o plantio (DAP).

\section{CONCLUSÕES}

As plantas daninhas avaliadas afetam o desenvolvimento da cultura competindo e interferindo no desenvolvimento vegetativo do grãode-bico;

As espécies $D$. nuda, E. indica e A. viridis causaram as maiores interferências sobre o grão-debico, seguidas pelo B. pilosa, $R$. raphanistrum, e $C$. rotundus. Segundo a análise de componentes principais a interferência das plantas daninhas afetou principalmente a área foliar do grão-de-bico.

\section{AGRADECIMENTOS}

À Fundação de Amparo à Pesquisa do Estado de São Paulo (FAPESP) (proc. \#2010/14018-0 e \#2008/11235-0) pela concessão de bolsas de mestrado e de iniciação científica a CLA, e ao Conselho Nacional de Desenvolvimento Científico e Tecnológico (CNPq) pela concessão de bolsa de pesquisador a PLCAA.

\begin{abstract}
The grains of chickpea consumed in Brazil are almost entirely imported. Considering that chickpeas presents conditions to be cultivated in some regions of Brazil, this study aimed to study interference of six weed plants (Amaranthus viridis, Bidens pilosa, Raphanus raphanistrum, Cyperus rotundus, Digitaria nuda and Eleusine indica) on the vegetative development of chickpeas. Thus, we evaluated the shoot length, number of leaves, leaf area, chlorophyll content and dry weight of leaves, stem and root of chickpeas. We observed a significant interference on the chickpeas' development in coexistence with weeds. Among the weeds, D. nuda, E. indica and A. viridis were the most aggressive, highlighting the need for early control of weeds when in cultivation of chickpeas in areas with a history of high density of these weeds. The leaf area of chickpeas was the most affected trait by the coexistence with weeds, affecting the development of the crop.
\end{abstract}

\title{
KEYWOR
REFERÊNCIAS
}

AGOSTINETTO, D.; GALON, L.; MORAES, P. V. D.; RIGOLI, R. P.; TIRONI, S. P.; PANOZZO, L. E. Competitividade relativa entre cultivares de arroz irrigado e biótipos de capim-arroz (Echinochloa spp.). Planta Daninha, Rio de Janeiro, v. 26, n. 4, p. 757-766, 2008. 
BAKER, N. R.; ROSENQVIST, E. Applications of chlorophyll fluorescence can improve crop production strategies: an examination of future possibilities. Journal of Experimental Botany, Oxford, v. 55, p. 16071621, 2004. http://dx.doi.org/10.1093/jxb/erh196

BAUCOM, R. S.; HOLT, J. S. Weeds of agricultural importance: bridging the gap between evolutionary ecology and crop and weed science. New Phytologist, v. 184, p. 741-743, 2009. http://dx.doi.org/10.1111/j.14698137.2009.03077.x

BHAN, V. M.; KUKULA, S. Weeds and their control in chickpea. In: SAXENA, M. C.; SINGH, K. B. (Ed.). The chickpea. Wallingford: C.A.B. International, 1987. p. 319-328.

CAMPOS, T.; CANÉCCHIO FILHO, V. Principais culturas. Campinas: Instituto Campineiro de Ensino Agrícola, 1987, v. 2, p. 95-99.

FAO. Food and Agriculture Organization of The United Nations. Base de dados FAOSTAT. Disponível em: <http://faostat.fao.org>. Acesso em: 17 ago. 2014.

FLECK, N. G.; AGOSTINETTO, D.; GALON, L.; SCHAEDLER, C. E. Competitividade relativa entre cultivares de arroz irrigado e biótipo de arroz-vermelho. Planta Daninha, Rio de Janeiro, v. 26, n. 1, p. 101111, 2008.

FORMAGIO, A. S. N.; MASETTO, T. E.; VIEIRA, M. C.; ZÁRATE, N. A. H.; COSTA, W. F.; TREVIZAN, L. N. F.; SARRAGIOTTO, M. H. Potencial alelopático de Tropaeolum majus L. na germinação e crescimento inicial de plântulas de picão-preto. Ciência Rural, Santa Maria, v. 42, n. 1, p. 83-89, 2012.

http://dx.doi.org/10.1590/S0103-84782011005000148

GIORDANO, L. B.; NASCIMENTO, W. M. Cícero: nova cultivar de grão-de-bico para cultivo de inverno. Horticultura Brasileira, Brasília, v. 12, n. 1, p. 80, 1994.

ICARDA-FSP. International Center for Agricultural Research in the Dry Areas. Farming System Program, annual report. Aleppo (Syria), 1986.

KAISER, H. F. The varimax criterion for analytic rotation in factor analysis. Psychometrika, v. 23, p. 178200, 1958. http://dx.doi.org/10.1007/BF02289233

LORENZI, H. Plantas daninhas e seu controle na cultura da cana-de-açúcar. In: REUNIÃO TÉCNICA AGRONÔMICA, 1983, Piracicaba. Anais... Piracicaba: Copersucar, 1983. p. 58-73.

MESCHEDE, D. K.; OLIVEIRA JR., R. S.; CONSTANTIN, J.; SCAPIM, C. A. Período anterior a interferência de plantas em soja: estudo de caso com baixo estande e testemunhas duplas. Planta Daninha, Rio de Janeiro, v. 22, n. 2, p. 239-246, 2004.

MIYASAKA, S.; MASCARENHAS, H. A. A. Cultura do grão-de-bico. Campinas: Instituto Agronômico de Campinas, 1977, p. 8. (Boletim, 168).

MUNIZ, F. R.; CARDOSO, M. G.; VON PINHO, E. V. R.; VILELA, M. Qualidade fisiológica de sementes de milho, feijão, soja e alface na presença de extrato de tiririca. Revista Brasileira de Sementes, Brasília, v. 29, n. 2, p. 195-204, 2007. http://dx.doi.org/10.1590/S0101-31222007000200026

NASCIMENTO, W. M.; GIORDANO, L. B.; BEVITORI, R. Avaliação de cultivares de grão-de-bico. Horticultura Brasileira, Brasília, v. 12, n. 1, p. 93, 1994.

OERKE, E. C. Crop losses to pests. Journal of Agricultural Science, Cambridge, p. 31-43, 2005. 
ROUSH, M. L. RADOSEVICH, S. R.; WAGNER, R. G.; MAXWELL, B. D.; PETERSEN, T. D. A comparison of methods for meauring effects of density and proporcion in plant competition experiments. Weed Science, champaign, v. 37, n. 2, p. 268-275, 1989.

SAXENA, M. C.; SUBRAMANIYAM, K. K.; YADAV, D. S. Chemical and mechanical control of weeds in gram (Cicer arietinum L.) . Pantnagar Journal of Research, v. 1, p. 112-116, 1976.

SOLH, M. B.; PALA, M. Weed control in chickpea. Aleppo (Syria): ICARDA - International Center for Agricultural Research in the Dry Areas, 1990. p. 93-99. (CIHEAM - Options Mediterraneennes, 9).

TEIXEIRA, I. R.; SILVA, R. P.; SILVA, A. G.; FREITAS, R. S. Competição entre feijoeiros e plantas daninhas em função do tipo de crescimento dos cultivares. Planta Daninha, Rio de Janeiro, v. 27, n. 2, p. 235240, 2009.

VAN RAIJ, B.; CANTARELLA, H.; QUAGGIO, J. A.; FURLANI, A. M. C. Recomendações de adubação e calagem para o Estado de São Paulo. 2. ed. Campinas: Instituto Agronômico, 1997. 285 p. (IAC. Boletim Técnico, 100).

VIDAL, R. A.; SPADER, V.; FLECK, N. G.; MEROTTO JR., A. Nível de dano econômico de Brachiaria plantaginea na cultura de milho irrigado. Planta Daninha, Rio de Janeiro, v. 22, n. 1, p. 63-69, 2004.

ZANATTA, J. F.; FIGUEIREDO, S.; FONTANA, L. C.; PROCÓPIO, S. O. Interferência de plantas daninhas em culturas olerícolas. Revista da FZVA, v. 13, n. 2, p. 39-57, 2006.

ZIMDAHL, R. L. Weed-Crop competition - A Review, second edition. Blackwell Publishing, IOWA, USA, 2004. 